\title{
Anti-high mobility group box 1 monoclonal antibody suppressed hyper-permeability and cytokine production in human pulmonary endothelial cells infected with influenza A virus
}

\author{
Takahiro Namba ${ }^{1}$ Mitsuru Tsuge ${ }^{1}$ (1) $\cdot$ Masato Yashiro $^{1} \cdot$ Yukie Saito $^{1} \cdot$ Keyue Liu $^{2} \cdot$ Masahiro Nishibori $^{2}$. \\ Tsuneo Morishima ${ }^{3} \cdot$ Hirokazu Tsukahara ${ }^{1}$
}

Received: 19 February 2021 / Revised: 18 July 2021 / Accepted: 20 August 2021 / Published online: 29 August 2021

(c) The Author(s), under exclusive licence to Springer Nature Switzerland AG 2021

\begin{abstract}
Objective High mobility group box-1 (HMGB1) has been reported to be involved in influenza A virus-induced acute respiratory distress syndrome (ARDS). We studied the efficacy of an anti-HMGB1 mAb using an in vitro model of TNF- $\alpha$ stimulation or influenza A virus infection in human pulmonary microvascular endothelial cells (HMVECs).

Methods Vascular permeability of HMVECs was quantified using the Boyden chamber assay under tumor necrosis factor- $\alpha$ $(\mathrm{TNF}-\alpha)$ stimulation or influenza A virus infection in the presence of anti-HMGB1 mAb or control mAb. The intracellular localization of HMGB1 was assessed by immunostaining. Extracellular cytokine concentrations and intracellular viral mRNA expression were quantified by the enzyme-linked immunosorbent assay and quantitative reverse transcription PCR, respectively.

Results Vascular permeability was increased by TNF- $\alpha$ stimulation or influenza A infection; HMVECs became elongated and the intercellular gaps were extended. Anti-HMGB1 mAb suppressed both the increase in permeability and the cell morphology changes. Translocation of HMGB1 to the cytoplasm was observed in the non-infected cells. Although anti-HMGB1 mAb did not suppress viral replication, it did suppress cytokine production in HMVECs.

Conclusion Anti-HMGB1 mAb might be an effective therapy for severe influenza ARDS.
\end{abstract}

Keywords Influenza $\cdot$ Acute respiratory distress syndrome $\cdot$ High mobility group box $1 \cdot$ Human pulmonary microvascular endothelial cell $\cdot$ Cytokine $\cdot$ Tumor necrosis factor- $\alpha$

\section{Introduction}

Influenza infection is prevalent every year worldwide and its complications, such as influenza pneumonia and acute respiratory distress syndrome (ARDS), impart high mortality

Responsible Editor: Masaru Ishii.

Mitsuru Tsuge

tsugemitsuru@okayama-u.ac.jp

1 Department of Pediatrics, Okayama University Graduate School of Medicine, Dentistry, and Pharmaceutical Sciences, 2-5-1 Shikata-cho, Kita-ku, Okayama 700-8558, Japan

2 Department of Pharmacology, Okayama University Graduate School of Medicine, Dentistry and Pharmaceutical Sciences, Okayama, Japan

3 Department of Pediatrics, Aichi Medical University, Nagakute, Japan rates [1, 2]. Influenza A (H1N1) pdm09 virus infection caused a pandemic in 2009 , resulting in $100,000-400,000$ deaths worldwide due to severe ARDS [3]. In the pathophysiology of influenza ARDS, direct viral infection and the subsequent hypercytokinemia response, induced by tumor necrosis factor-alpha (TNF- $\alpha$ ) or interleukin-6 (IL-6), activate host immunity, damage pulmonary vascular endothelial cells, and increase vascular leakage resulting in pulmonary edema [4-6]. Damage to the barrier of endothelial cells can lead to leakage by micro-vessels [4-6]. Here, we aimed to determine how to prevent damages to the endothelial cells to suppress the progression of influenza-associated ARDS.

In the past decade, various treatments have been developed to prevent the severity of influenza pneumonia [2,7]. One treatment involves anti-influenza drugs that directly decrease the replication of influenza virus [8]. A second treatment involves therapeutic lung protection strategies, such as extracorporeal membrane oxygenation (ECMO), 
to alleviate lung damage caused by ventilator-induced lung injury [7]. A third treatment involves anti-inflammatory therapy for hypercytokinemia caused by influenza infection $[2,9,10]$. Various immunomodulators have been developed to date, but they have not yet been put into practical use in the treatment of influenza pneumonia $[9,10]$. A certain number of patients develop severe progressive ARDS despite the administration of anti-influenza drugs with ECMO treatment, and they exhibit high mortality rates [2, 11, 12]. Therefore, there is a strong need for the development of novel therapeutic immunomodulatory drugs that can be used in combination with anti-influenza drugs.

Relatively high levels of serum high mobility group box-1 (HMGB1) were reported in patients with severe influenza pneumonia [13] as also observed under various inflammatory conditions, such as sepsis $[14,15]$ and acute lung inflammation [16]. HMGB1 is a damage-associated molecular pattern (DAMP) protein [14, 15, 17]. HMGB1 can promote the production of inflammatory cytokines, such as TNF- $\alpha$ or IL-6, via the receptor for the advanced glycation end product (RAGE) and toll-like receptor 4 (TLR-4) $[15,17]$. Several studies show that HMGB1 would function as a major proinflammatory mediator in these inflammatory conditions [14-17]. Therefore, the possibility of inhibiting the function of HMGB1 has been suggested as a therapeutic intervention [16]. We previously reported that an anti-HMGB1 mAb improved the survival rate and inhibited cytokine/chemokine expression in the lungs of a mouse model of influenza pneumonia [18]. We also reported that the efficacy of the combined therapy of an anti-influenza drug and an anti-HMGB1 antibody improved the survival rate more than that of anti-influenza drug mono-therapy [19]. The cytokine concentration in the blood and alveolar lavage fluid was also decreased by this combined therapy [19]. In these reports, the efficacy of anti-HMGB1 antibody in vivo was clarified; however, it has not yet been verified in human primary lung endothelial cells in vitro.

Therefore, the aim of this study was to assess the efficacy of an anti-HMGB1 mAb on an in vitro model of severe influenza pneumonia. We stimulated human pulmonary vascular endothelial cells (HMVECs) with TNF- $\alpha$ to induce hypercytokinemia or infected them with influenza A virus, in the presence of anti-HMGB1 mAb or control antibody. We evaluated the permeability, the changes in cell morphology and cytokine production of HMVECs.

\section{Materials and methods}

\section{Cell culture}

Primary HMVECs (Lonza, Walkersville, MD, USA) were grown in the medium and growth supplements supplied by the manufacturer (endothelial cell basal medium 2; EGM-2) containing the following: vascular endothelial growth factor, human fibroblast growth factor B, hydrocortisone, human epidermal growth factor, GA-1000, fetal bovine serum, rat insulin-like growth factor 1 , and ascorbic acid [20, 21]. The medium was changed every $48 \mathrm{~h}$ until confluence was reached. The cells were cultured in $5 \% \mathrm{CO}_{2}$ at $37{ }^{\circ} \mathrm{C}$. All experiments were performed on cells in the 5 th- -9 th passage.

\section{Viruses}

We used influenza A (H3N2) virus (A/Panama/1/68) maintained in Madin-Darby canine kidney (MDCK) cells. The influenza virus was titrated to determine the median tissue culture infectivity dose $\left(\mathrm{TCID}_{50}\right)$ of MDCK cells in the presence of trypsin. We diluted the influenza virus tenfold in steps, applied to MDCK cell monolayers in triplicate, and evaluated the cytopathic effects 5 days after infection. The viral infection procedure was performed at multiplicities of infection (MOI) 1 in serum-free media with $0.5 \%$ bovine serum albumin (BSA).

\section{Permeability assay}

A Boyden chamber was used for the evaluation of permeability [22, 23]. HMVECs were seeded on $0.4 \mathrm{~mm}$ pore size polyethylene terephthalate track-etched transwell membranes (Corning, NY, USA) at a concentration of $1.0 \times 10^{5}$ cells/well and cultured to confluency for 3-4 days. After cell confluence was achieved, the culture media in the upper chamber $(200 \mu \mathrm{L})$ and the lower chamber $(700 \mu \mathrm{L})$ were replaced with serum-free media with $0.5 \%$ BSA containing human recombinant TNF- $\alpha$ (Peprotech Inc., Rocky Hill, NJ, USA) at a concentration of $100 \mathrm{ng} / \mathrm{mL}$ for $24 \mathrm{~h}$, or influenza virus at MOI of 1 for $72 \mathrm{~h}$. At this time, the media in the upper and the lower chamber contained either anti-HMGB1 $\mathrm{mAb}$ (\#10-22, immunoglobulin G2a subclass, $100 \mu \mathrm{g} / \mathrm{mL}$ ) or class-matched control mAb (anti-Keyhole Limpet hemocyanin, $100 \mu \mathrm{g} / \mathrm{mL}$ ) [24]. These mAbs were provided by Professor Nishibori, Department of Pharmacology, Okayama University Graduate School of Medicine. To measure permeability, $200 \mu \mathrm{L}$ assay medium containing fluorescein isothiocyanate-labeled dextran (FITC-Dx; MW 70,000) (Invitrogen Corp., Carlsbad, CA, USA) was added to each upper chamber, and $700 \mu \mathrm{L}$ assay medium was added to each lower chamber. After several hours of incubation, the fluorescence intensity of the lower chamber medium was measured at $485-538 \mathrm{~nm}$.

\section{Immunofluorescence staining}

HMVECs were grown to confluency on collagen I-coated culture slides (AGC TECHNO GLASS Co., Shizuoka, 
Japan). After the indicated treatment time, cells were washed with phosphate-buffered saline (PBS) and fixed with $4.0 \%$ paraformaldehyde for $15 \mathrm{~min}$. After permeabilization with $0.2 \%$ Triton X-100 in PBS for 10 min, the cells were washed and probed with the primary antibodies (mouse anti-influenza A nucleoprotein antibody from Abcam, Cambridge, MA, USA; rabbit anti-HMGB1 antibody from Abcam; and rabbit anti-vascular endothelial (VE) cadherin antibody from Abcam) at a 1:200 dilution for $60 \mathrm{~min}$. The coverslips were washed and then incubated with Alexa Fluor 488-conjugated goat anti-rabbit or anti-mouse secondary antibody (1:500 dilution) (Invitrogen Corp., Carlsbad, CA, USA) for $1 \mathrm{~h}$ at $20^{\circ} \mathrm{C}$. The nuclei were stained with $4^{\prime}, 6$-diamidino2-phenylindole (DAPI) in a mounting medium (Vectashield; Vector Laboratories Inc., Burlingame, CA, USA). Samples were evaluated under a fluorescence microscope (BZ-9000 generation II; Keyence Co., Osaka, Japan). When measuring the cell morphology, each long axis and short axis of 100 cells/field at $40 \times$ magnification were measured on the VE cadherin-stained images using the BZ image analysis software application. The same measurements were performed on four randomly selected fields of view.

\section{Quantitative reverse transcription PCR (qRT-PCR)}

Total RNA was extracted at $6,12,18$, and $72 \mathrm{~h}$ after influenza infection using the RNeasy Mini Kit (Qiagen, Carlsbad, CA, USA) with DNase digestion. cDNA synthesis was carried out using the TaKaRa PrimeScript first-strand cDNA synthesis kit (Takara Bio Inc., Kusatsu, Japan) according to the manufacturer's instructions. qRT-PCR was conducted using PowerUp SYBR Green PCR Master Mix (Applied Biosystems, Foster City, CA, USA). cDNA was denatured at $50{ }^{\circ} \mathrm{C}$ for $2 \mathrm{~min}$ and $95{ }^{\circ} \mathrm{C}$ for $2 \mathrm{~min}$ followed by 40 cycles of $95^{\circ} \mathrm{C}$ for $15 \mathrm{~s}$ and $60{ }^{\circ} \mathrm{C}$ for 1 min using the RealTime PCR system 7500 (Applied Biosystems). Data were analyzed using SDS software v2.1 (Applied Biosystems). Relative gene expression was compared using the comparative CT method. Glyceraldehyde 3-phosphate dehydrogenase (GAPDH) was used to normalize the efficiency of cDNA synthesis. The primer sets used for this study were influenza A M1: forward 5'-AAGACCAATCCTGTCACCTCTGA-3' and reverse 5'-CAAAGCGTCTACGCTGCAGTCC-3'; and GAPDH: forward 5'-GTCTCCTCTGACTTCAACAGCG-3' and reverse 5'-ACCACCCTGTTGCTGTAGCCAA-3'.

\section{Enzyme-linked immunosorbent assay (ELISA)}

Supernatants were collected at different time points after stimulation with TNF- $\alpha$ or infection with influenza A virus. The levels of HMGB1, IL-6, granulocyte colony-stimulating factor (G-CSF), granulocyte-macrophage CSF (GM-CSF), regulated on activation, normal $\mathrm{T}$ cell expressed and secreted
(RANTES), and interferon- $\gamma$ inducible protein (IP-10) were measured using commercial ELISA kits (HMGB1: Shinotest, Kanagawa, Japan; IL-6, G-CSF, GM-CSF, RANTES, IP-10: R\&D Systems, Minneapolis, MN, USA) according to the manufacturer's instructions.

\section{Cell viability assay}

HMVECs were seeded on $96-$ well plates. TNF- $\alpha$ stimulation and influenza A (H3N2) infection were performed at the indicated concentrations. Cell viability was then measured using MTT [3-(4,5-dimethyl-2-thiazolyl)-2,5-diphenyltetrazolium bromide] cell count kit (NACALAI TESQUE, INC., Kyoto, Japan) according to the manufacturer's instructions. The absorbance $(570 \mathrm{~nm})$ of each sample was measured by a microplate reader, and the measured absorbance was corrected using a background control.

\section{Quantification of HMGB1 translocation}

To quantify HMGB1 translocation, the number of HMGB1 cytoplasmic translocations per 100 cells at $40 \times$ magnification was measured in the HMGB1-stained images. The same measurements were performed on four randomly selected fields of view.

\section{Statistical analyses}

All experiments were performed at least three times and all values are expressed as mean \pm standard error (SE). Data were analyzed using GraphPad Prism software version 8.0 for Mac (GraphPad Software, San Diego, CA, USA). Differences between groups were examined for statistical significance using one-way analysis of variance with Tukey's multiple comparison test. Statistical significance was inferred for $P$ values $<0.05$.

\section{Results \\ Influenza A virus infection of human pulmonary microvascular endothelial cells}

HMVECs were treated with influenza A $(\mathrm{H} 3 \mathrm{~N} 2)$ at $\mathrm{MOI}=1$. No staining of viral nucleoprotein (NP) was observed in HMVECs without influenza A (H3N2) infection. NP-positive cells were found in approximately 10\% of HMVECs infected with influenza A (H3N2) at MOI = 1, whereas NPpositive cells were found in almost all HMVECs infected at MOI $=10$ (Fig. 1a-f). Viral NP was stained in both the nucleus and the cytoplasm of HMVECs. 


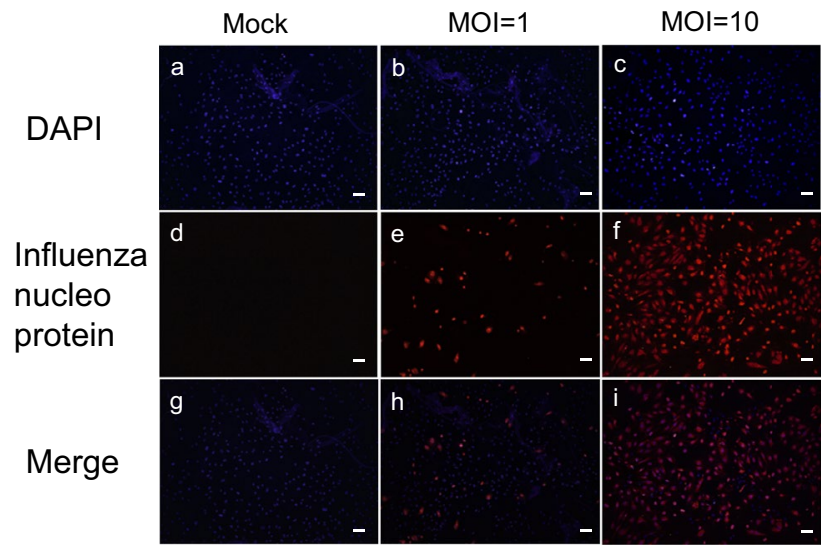

Fig. 1 Human pulmonary microvascular endothelial cells (HMVECs) infected with influenza A viruses. Influenza A nucleoprotein was stained in HMVECs $12 \mathrm{~h}$ after infection with influenza A (H3N2). The nuclei were stained with DAPI. a, d No infection, b, e influenza $A(\mathrm{H} 3 \mathrm{~N} 2)$ at $\mathrm{MOI}=1$, c, f influenza $\mathrm{A}(\mathrm{H} 3 \mathrm{~N} 2)$ at $\mathrm{MOI}=10$. HMVECs were stained with an anti-influenza A nucleoprotein antibody. Scale bar $100 \mu \mathrm{m}$

\section{HMGB1 release was increased after TNF-a stimulation or influenza $A$ infection}

HMVECs were stimulated with TNF- $\alpha(100 \mathrm{ng} / \mathrm{mL})$ for 0,12 , and $24 \mathrm{~h}$, or infected with influenza A (H3N2) at $\mathrm{MOI}=1$ for 0,24 , and $48 \mathrm{~h}$. The HMGB1 concentration in the supernatant had significantly increased after $12 \mathrm{~h}$ of TNF- $\alpha$ stimulation compared with that at $0 \mathrm{~h}$. Similarly, the HMGB 1 concentration in the supernatant had significantly increased after $24 \mathrm{~h}$ compared with that at $12 \mathrm{~h}$ (Fig. 2a). The HMGB1 concentration in the supernatant was significantly increased after $24 \mathrm{~h}$ of influenza A (H3N2) infection compared with that at $0 \mathrm{~h}$, and at $48 \mathrm{~h}$ compared with that at $24 \mathrm{~h}$ (Fig. 2b).

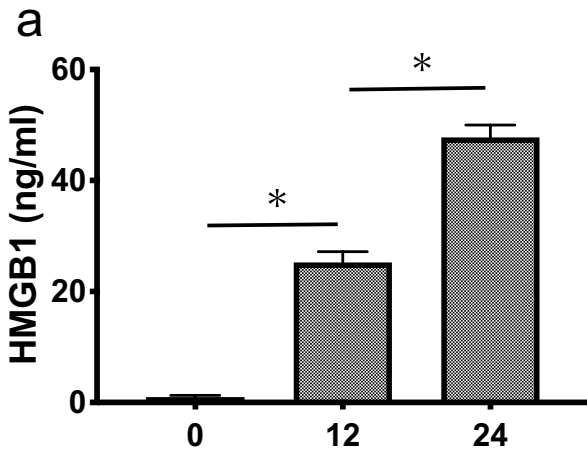

Time after TNF- $\alpha$ stimulation (hr)

Fig. 2 High mobility group box-1 (HMGB1) release was increased after TNF- $\alpha$ stimulation or influenza A infection. a HMGB1 concentrations in the supernatant of HMVECs at 0, 12, and $24 \mathrm{~h}$ after stimulation with TNF- $\alpha(100 \mathrm{ng} / \mathrm{mL})$, and b HMGB1 concentra-

\section{Viability of human pulmonary microvascular endothelial cells did not decrease after TNF- $a$ stimulation or influenza $A$ infection}

HMVECs were stimulated with TNF- $\alpha(100 \mathrm{ng} / \mathrm{mL}$ or $10 \mathrm{ng} / \mathrm{mL}$ ) for $24 \mathrm{~h}$ or infected with influenza A (H3N2) virus at an MOI of 0.1 or 1.0 for $72 \mathrm{~h}$. We did not observe any significant difference in cell viability upon TNF- $\alpha$ stimulation as well as in influenza A virus infection (Fig. 3a, b).

\section{HMGB1 was translocated to the cytoplasm after TNF-a stimulation or influenza A infection}

HMVECs were stimulated with TNF- $\alpha(100 \mathrm{ng} / \mathrm{mL})$ for $6 \mathrm{~h}$ or infected with influenza A $(\mathrm{H} 3 \mathrm{~N} 2)$ at $\mathrm{MOI}=1$ for $12 \mathrm{~h}$. Cytoplasmic translocation of HMGB1 was observed in a few HMVECs after TNF- $\alpha$ stimulation (Fig. $4 \mathrm{a}-\mathrm{d}$ ) and influenza A (H3N2) infection. Cytoplasmic translocation of HMGB1 was higher in cells after influenza A (H3N2) infection than that after TNF- $\alpha$ stimulation. In infected cells, HMGB1 remained in the nucleus. Interestingly, the cytoplasmic translocation was observed not in the infected cells but in the surrounding non-infected cells (Fig. 5a-d). The translocation of HMGB1 was not observed in the absence of TNF- $\alpha$ stimulation or influenza A (H3N2) infection (Figs. 4e-h, 5e-h).

The translocation of HMGB1 was observed in HMVECs either upon TNF- $\alpha$ stimulation or influenza A (H3N2) infection (TNF- $\alpha ; 1.9 \pm 0.39 / 100$ cells, Influenza A infection; $2.78 \pm 0.45 / 100$ cells). The HMGB 1 translocation was not observed in the absence of TNF- $\alpha$ stimulation or influenza A (H3N2) infection (Fig. 6a, b).

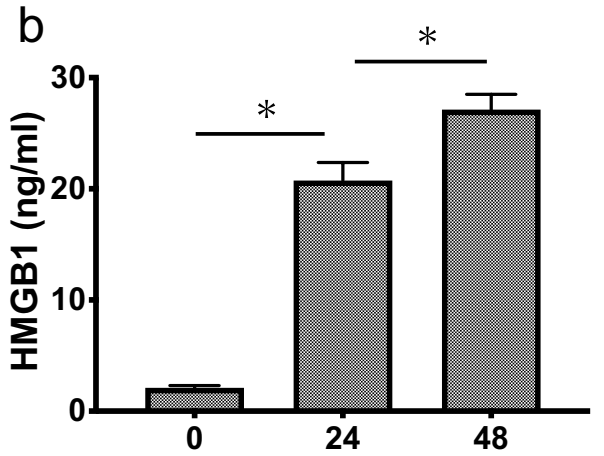

Time after influenza A(H3N2) infection (hr)

tions in the supernatant of HMVECs at 0,24 , and $48 \mathrm{~h}$ after infection with influenza A $(\mathrm{H} 3 \mathrm{~N} 2)$ at $\mathrm{MOI}=1 . N=4$ in each group. All results are expressed as the mean \pm SEM of three different experiments. $* p<0.05$ by ANOVA with Tukey's multiple comparison test 
Fig. 3 Viability of HMVECs did not decrease after TNF- $\alpha$ stimulation or influenza A infection. The viability of HMVECs was measured a $24 \mathrm{~h}$ after stimulation of TNF- $\alpha(10 \mathrm{ng} / \mathrm{ml}$ or $100 \mathrm{ng} / \mathrm{mL}$ ) or $\mathbf{b} 72 \mathrm{~h}$ after infection of influenza A (H3N2) $(\mathrm{MOI}=0.1$ or $\mathrm{MOI}=1)$.

Results are expressed as the mean \pm SEM of three independent experiments a

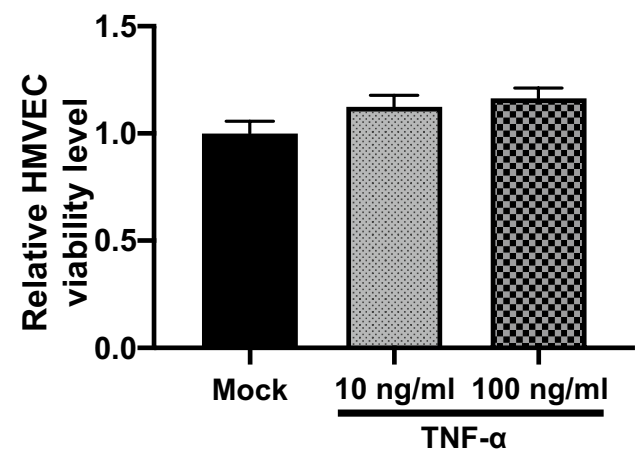

b

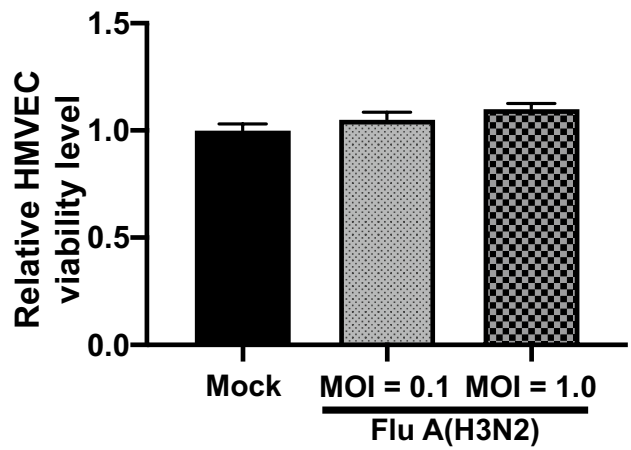

Fig. 4 TNF- $\alpha$ stimulation induced the translocation of HMGB1. HMGB1 was stained in HMVECs $6 \mathrm{~h}$ after stimulation with TNF- $\alpha(100 \mathrm{ng} / \mathrm{mL})$ or without TNF- $\alpha$ stimulation. a, e HMGB1 staining, b, f DAPI, $\mathbf{c}, \mathbf{g}$ merged, and $\mathbf{d}, \mathbf{h}$ magnified image of $\mathbf{c}$ or $\mathbf{g}$ inside the dotted line. The white arrowhead indicates the translocation of HMGB1. Scale bar $50 \mu \mathrm{m}$

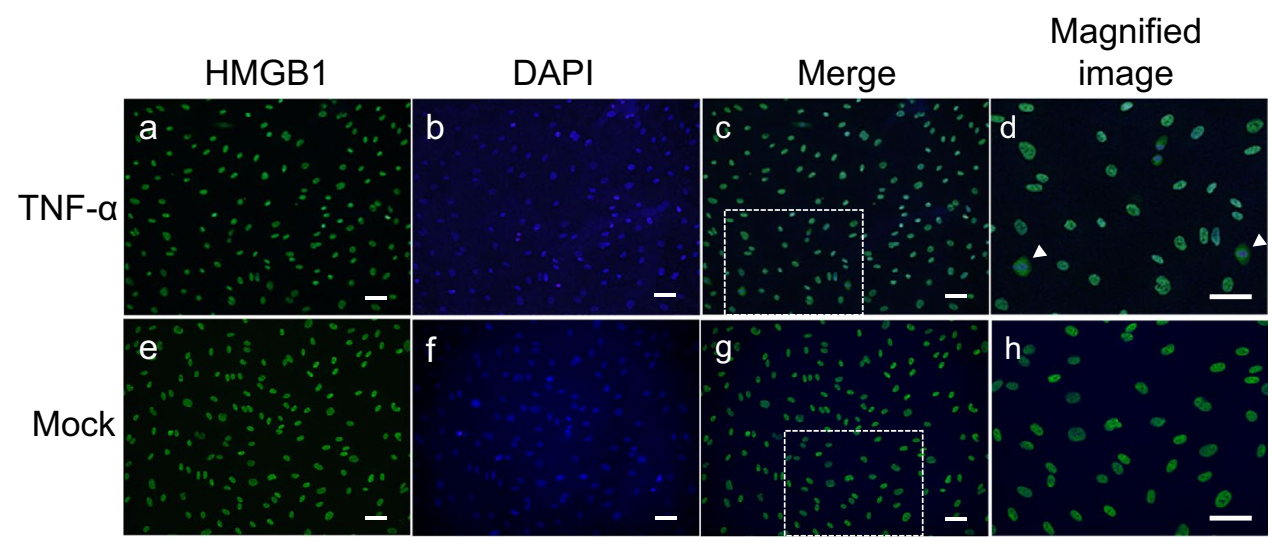

\section{Anti-HMGB1 mAb suppressed human pulmonary endothelial vascular permeability after TNF-a stimulation or influenza $A$ infection}

The vascular permeability of HMVECs was increased upon TNF- $\alpha$ stimulation $(100 \mu \mathrm{g} / \mathrm{mL}$, for $24 \mathrm{~h})$, but it was significantly suppressed in the presence of anti-HMGB 1 $\mathrm{mAb}(100 \mathrm{ng} / \mathrm{mL})(p<0.05)$ (Fig. 7a). The permeability of HMVECs also increased upon influenza A (H3N2) infection (MOI $=1$, for $72 \mathrm{~h}$ ), and it was significantly suppressed in the presence of anti-HMGB1 mAb $(p<0.05)$ (Fig. 7b).

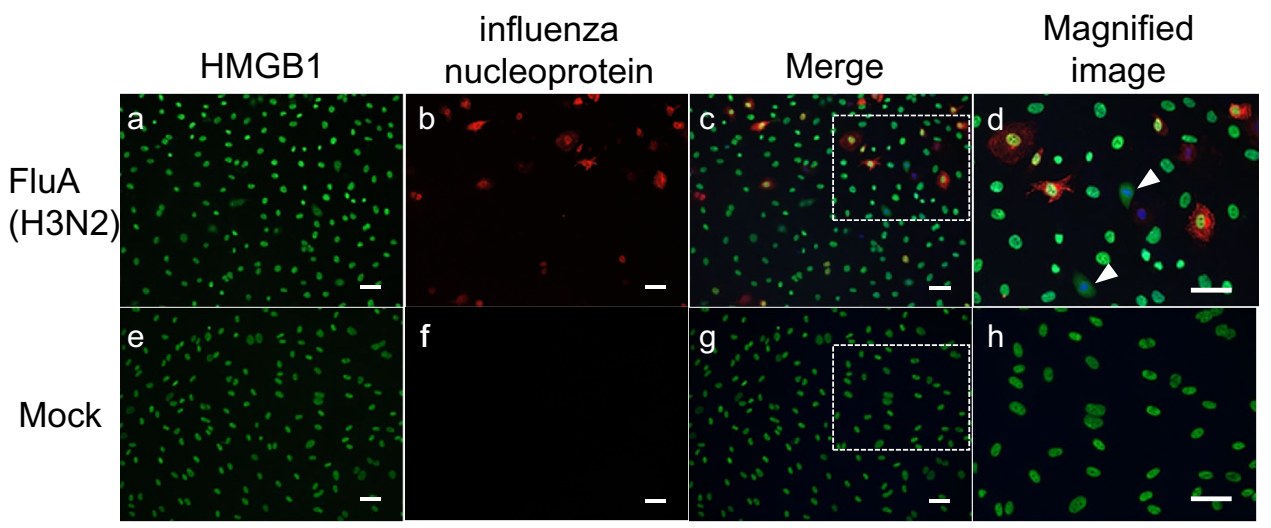

Fig. 5 Influenza A infection induced the translocation of HMGB1 in the surrounding non-infected cells. HMGB1 and influenza nucleoprotein were stained in HMVECs $12 \mathrm{~h}$ after infection with influenza A $(\mathrm{H} 3 \mathrm{~N} 2)$ at an $\mathrm{MOI}=1$ or without influenza A (H3N2) infection. a, e HMGB1; b, f influenza nucleoprotein; c, $\mathbf{g}$ merged; and $\mathbf{d}, \mathbf{h}$ magnified images of $\mathbf{c}$ or $\mathbf{g}$ inside the dotted line. HMGB1 is shown in green, and the viral nucleoprotein is shown in red. The white arrowhead indicates the translocation of HMGB1. Scale bar $50 \mu \mathrm{m}$ 
Fig. 6 Translocation of HMGB1 was observed in HMVECs upon TNF- $\alpha$ stimulation or influenza A infection. The number of HMVECs with HMGB1 translocation was counted $\mathbf{a}$ $6 \mathrm{~h}$ after stimulation of TNF- $\alpha$ $(100 \mathrm{ng} / \mathrm{mL})$ or b $12 \mathrm{~h}$ after infection with influenza A $(\mathrm{H} 3 \mathrm{~N} 2)(\mathrm{MOI}=1)$. Results are expressed as the mean \pm SEM of three independent experiments. Asterisk indicates statistically significant differences between the groups $(p<0.05)$

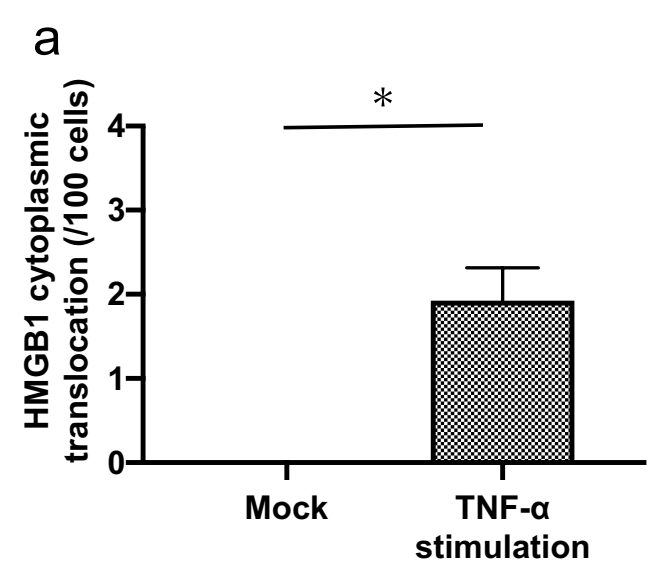

b
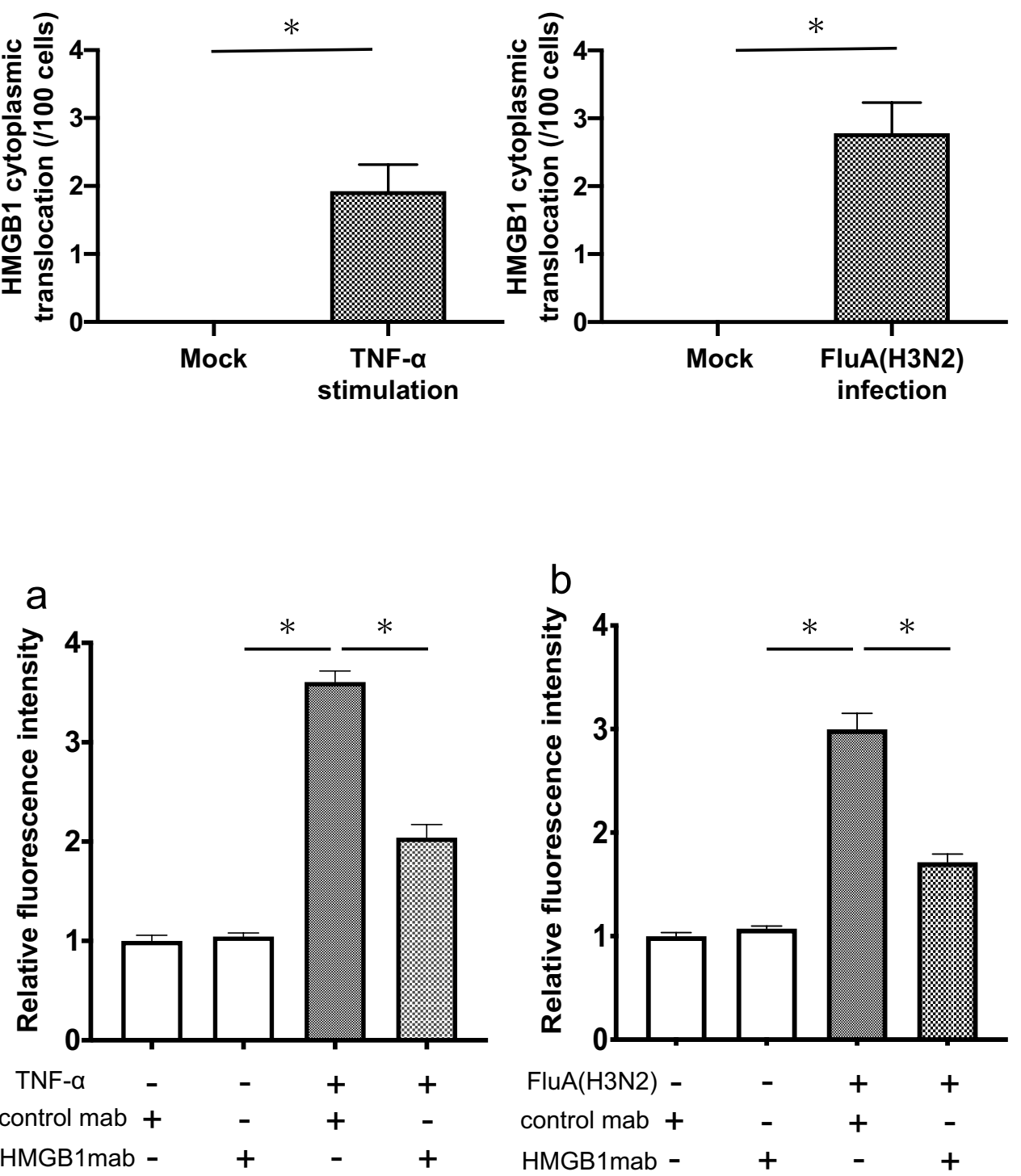

Fig. 7 Anti-HMGB1 mAb improved HMVEC permeability after TNF- $\alpha$ stimulation or influenza A infection. The vascular permeability of HMVECs were measured $24 \mathrm{~h}$ after stimulation of TNF- $\alpha(100 \mathrm{ng} / \mathrm{mL})$ or $72 \mathrm{~h}$ after infection of influenza A $(\mathrm{H} 3 \mathrm{~N} 2)(\mathrm{MOI}=1)$, in the presence of anti-HMGB1 mAb $(100 \mu \mathrm{g} / \mathrm{mL})$ or control antibody $(100 \mu \mathrm{g} / \mathrm{mL}) . N=4$ for each group. Results were normalized to the no stimulation or no infection group with the control $\mathrm{mAb}$. All results are expressed as the mean \pm SEM of three different experiments. ${ }^{*} p<0.05$ by ANOVA with Tukey's multiple comparison test

\section{Anti-HMGB1 mAb inhibited the spindle-shape change of HMVECs after TNF-a stimulation or influenza A infection}

In the absence of any stimulation, HMVECs showed a uniform cobblestone appearance with almost no intercellular spaces (Fig. 8a, d). Upon TNF- $\alpha$ stimulation (100 $\mu \mathrm{g} / \mathrm{mL}$, for $24 \mathrm{~h})$, HMVECs showed a cell spindle-shape change, which was significantly inhibited in the presence of anti-HMGB1 mAb $(p<0.05)$ (Fig. 8b, c). HMVECs also showed a cell spindleshape change after influenza A (H3N2) infection $(\mathrm{MOI}=1$, for $72 \mathrm{~h}$ ), which was significantly inhibited in the presence of anti-HMGB1 mAb $(p<0.05)$ (Fig. 8e, f).

\section{Anti-HMGB1 mAb inhibited the production of proinflammatory cytokines or chemokines after TNF-a stimulation or influenza $A$ infection}

The levels of IL-6, GM-CSF, G-CSF, IP-10, and RANTES were significantly increased in the supernatants of HMVECs upon TNF- $\alpha$ stimulation $(100 \mu \mathrm{g} / \mathrm{mL}$, for $24 \mathrm{~h}$ ). The increased levels of IL-6, GM-CSF, and IP-10 were significantly suppressed in the presence of anti-HMGB1 mAb (IL-6, GMCSF, and IP-10, $p<0.01$; G-CSF, $p<0.05$ ) (Fig. 9a-e). The levels of IL-6, GM-CSF, G-CSF, IP-10, or RANTES significantly increased in the supernatant of HMVECs infected with influenza $\mathrm{A}(\mathrm{H} 3 \mathrm{~N} 2)(\mathrm{MOI}=1$, for $72 \mathrm{~h})$, and the increased 
Fig. 8 Anti-HMGB1 mAb improved the spindle-shaped change of HMVECs after TNF- $\alpha$ stimulation or influenza A infection. HMVECs were stained with rabbit anti-vascular endothelial cadherin antibody under a variety of conditions. a Control antibody $(100 \mu \mathrm{g} /$ $\mathrm{mL}$ ) alone for $24 \mathrm{~h}$; $\mathbf{d}$ control antibody $(100 \mu \mathrm{g} / \mathrm{mL})$ alone for $72 \mathrm{~h}$; b, c TNF- $\alpha$ stimulation $(100 \mathrm{ng} / \mathrm{mL})$ for $24 \mathrm{~h}$; $\mathbf{e}$, f influenza A (H3N2) infection at $\mathrm{MOI}=1$ for $72-\mathrm{h}$. b, e HMVECs were treated with control mAb $(100 \mu \mathrm{g} / \mathrm{mL})$; c, $\mathbf{f}$ HMVECs were treated with HMGB1 mAb $(100 \mu \mathrm{g} /$ $\mathrm{mL}$ ). Length/width ratio of HMVECs g with TNF- $\alpha$ stimulation $(100 \mu \mathrm{g} / \mathrm{mL})$, and $\mathbf{h}$ with influenza A (H3N2) infection $(\mathrm{MOI}=1)$, in the presence of HMGB1 mAb $(100 \mu \mathrm{g} / \mathrm{mL})$ or control mAb $(100 \mu \mathrm{g} / \mathrm{mL})$. Results are expressed as the mean \pm SEM of three independent experiments. Asterisk indicates statistically significant differences between the groups $(p<0.05)$
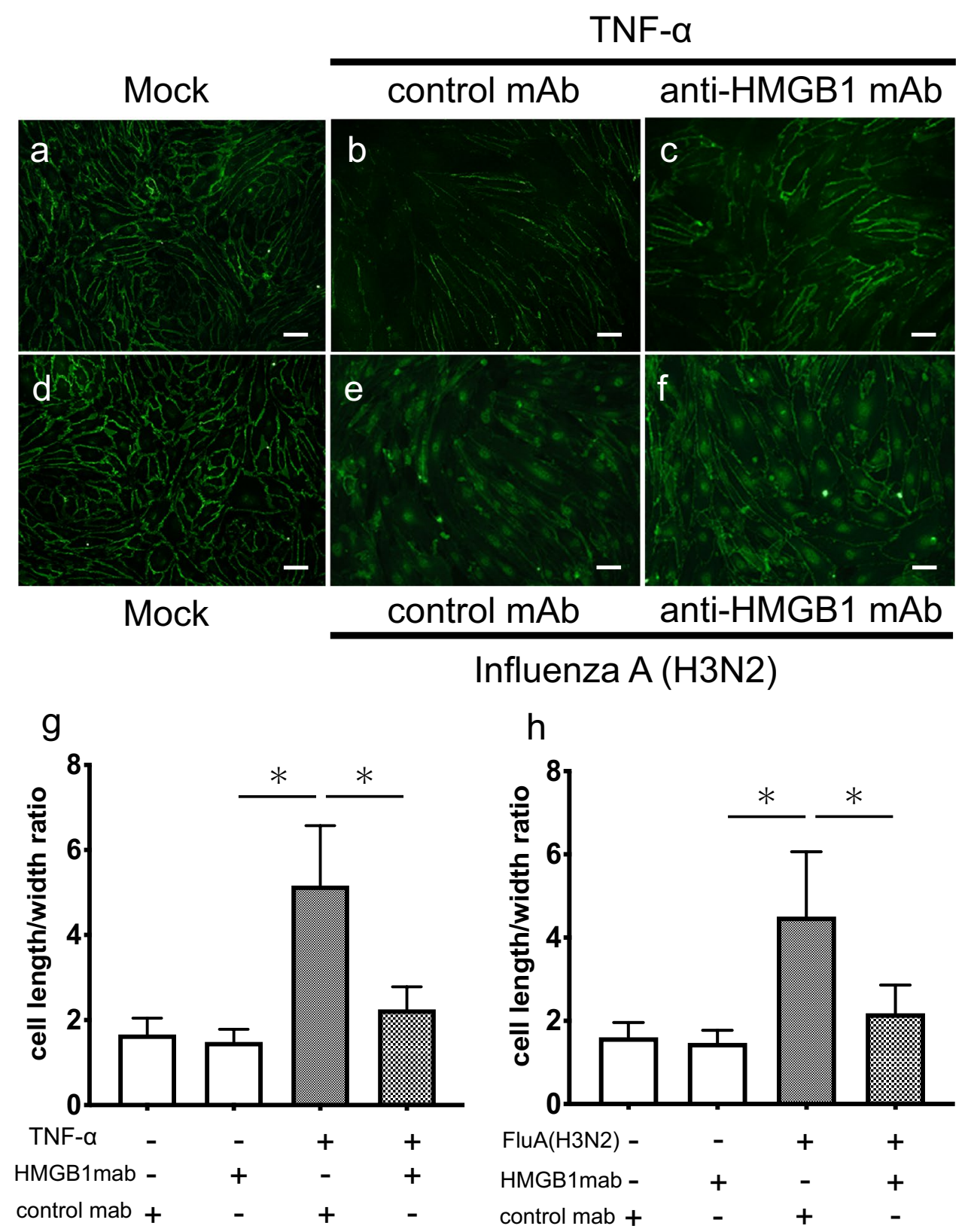

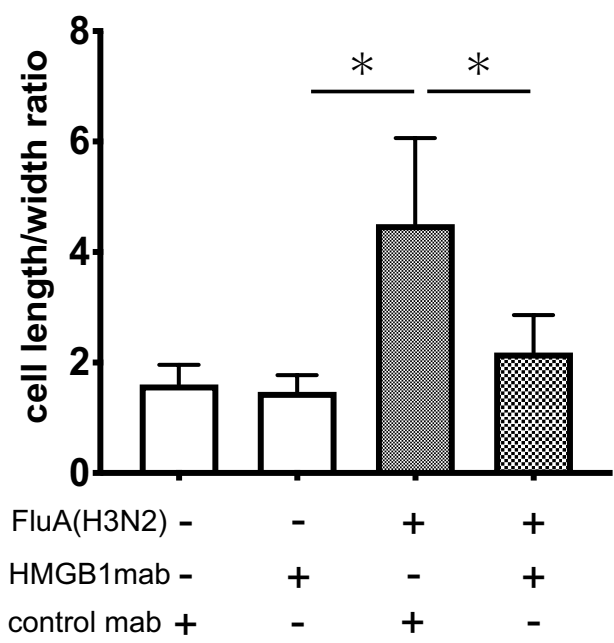

levels of IL-6, GM-CSF, and IP-10 were significantly suppressed in the presence of anti-HMGB1 mAb (IL-6, GMCSF, G-CSF, IP-10, $p<0.01$ ) (Fig. 9f-j).

\section{Viral gene expression of influenza M1 protein was not inhibited by anti-HMGB1 $\mathrm{mAb}$}

Viral gene expression of the influenza M1 protein was significantly increased at $12 \mathrm{~h}$ in a time-dependent manner after influenza A (H3N2) infection at MOI $=1(p<0.05)$. Viral M1 protein gene expression was not suppressed after influenza A (H3N2) infection in the presence of anti-HMGB1 $\mathrm{mAb}$ compared with that of the control mAb (Fig. 10).

\section{Discussion}

First, we confirmed that influenza A virus (H3N2) can infect HMVECs. This influenza A virus was able to infect more cells at $\mathrm{MOI}=10$ compared to $\mathrm{MOI}=1$, which agrees with previous reports $[21,23]$. Both $\alpha 2-3$ sialic acid and $\alpha 2-6$ sialic acid, which are receptors for the influenza virus to enter cells, are known to be expressed on the surfaces of HMVECs [21], and influenza infection of HMVECs has been observed in several studies [20, 21, 23, 25]. Previous autopsy reports of patients with influenza pneumonia confirmed that the influenza viral protein was located in a small number of pulmonary vascular endothelial cells [26]. 


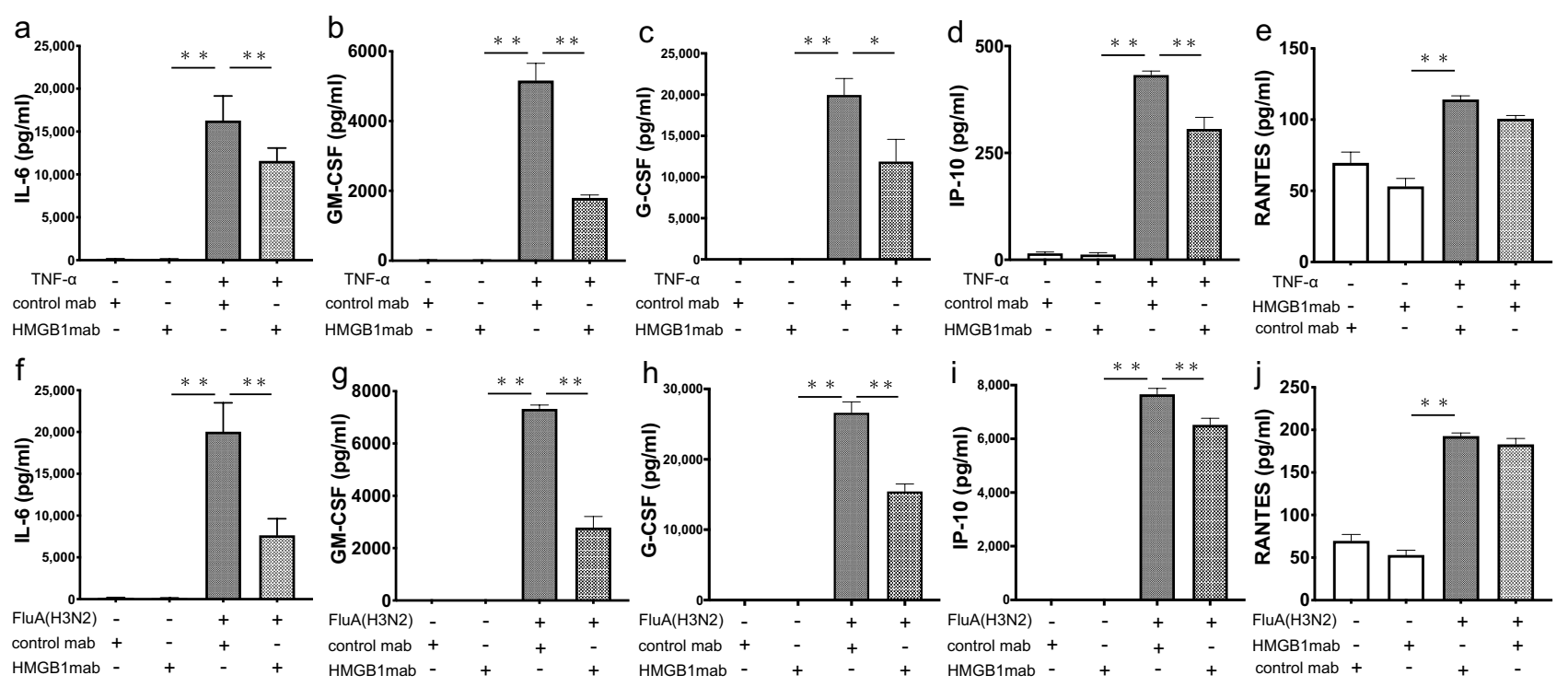

Fig. 9 Anti-HMGB1 mAb inhibited the production of proinflammatory cytokines or chemokines after TNF- $\alpha$ stimulation or influenza A infection. Cytokine concentrations in the supernatants of HMVECs $24 \mathrm{~h}$ after stimulation with TNF- $\alpha(100 \mathrm{ng} / \mathrm{mL})(\mathbf{a}-\mathbf{e})$ or $72 \mathrm{~h}$ after infection with influenza $\mathrm{A}(\mathrm{H} 3 \mathrm{~N} 2)(\mathbf{f}-\mathbf{j})$ at $\mathrm{MOI}=1$ with anti-

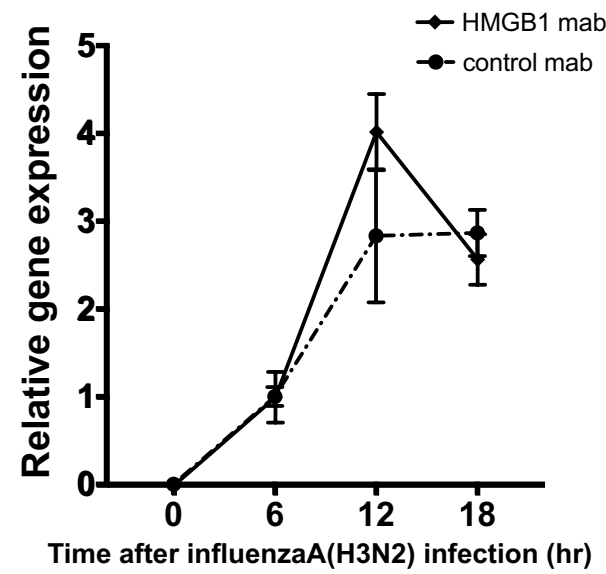

Fig. 10 Viral gene expression of influenza M1 protein was not changed by anti-HMGB1 mAb. Gene expression of viral M1 protein in HMVECs was measured at $0,6,12$, and $18 \mathrm{~h}$ after infection with influenza A $(\mathrm{H} 3 \mathrm{~N} 2)$ at $\mathrm{MOI}=1$ in the presence of anti-HMGB1 mAb $(100 \mu \mathrm{g} / \mathrm{mL})$ or control antibody $(100 \mu \mathrm{g} / \mathrm{mL})$. The relative gene expression was normalized to the level of glyceraldehyde-3-phosphate dehydrogenase (GAPDH). $n=4$ for each group. All results are expressed as the mean \pm SEM of three different experiments

We considered that the pathological condition in which a small number of HMVECs are infected with influenza more closely reflects the pathophysiology of severe influenza pneumonia in humans. Therefore, in this study, we infected HMVECs with influenza $\mathrm{A}$ at $\mathrm{MOI}=1$ to enable an analysis of the inter-relationship between influenza A virus-infected cells and uninfected cells.
HMGB1 mAb $(100 \mu \mathrm{g} / \mathrm{mL})$ or control antibody $(100 \mu \mathrm{g} / \mathrm{mL}) . n=4$ for each group. All results are expressed as the mean \pm SEM of three different experiments. ${ }^{*} p<0.05$, ${ }^{*} p<0.01$ by ANOVA with Tukey's multiple comparison test

We confirmed that TNF- $\alpha$ stimulation and influenza A infection induced the release of HMGB1 from HMVECs. We also confirmed that TNF- $\alpha$ stimulation and influenza A infection caused the translocation of HMGB1 protein from the nucleus to the cytoplasm. Interestingly, HMGB1 translocations were found in surrounding uninfected cells. Several previous reports suggest that HMGB1 could be released from various vascular endothelial cells by TNF- $\alpha$ stimulation [27] or by virus infection [28, 29]. Importantly, HMGB1 has been reported to be released from virus-infected cells in previous studies [28, 29], which is not consistent with our results. Cytoplasmic translocation of HMGB1 in HMVECs has not yet been investigated for influenza infection and this inconsistency might be due to differences in vascular endothelial cell types and virus types used in the studies. Our study results suggest that influenza A infection in a small number of HMVECs stimulates the transmission of a signal that causes cytoplasmic translocation of HMGB1 in surrounding uninfected cells. At the same time, HMGB1 protein was still found in the nucleus of infected cells, so it was considered possible that the increased HMGB1 in the supernatant was released from non-infected cells rather than from infected cells. The cytoplasmic translocation of HMGB1 has been reported to occur because of the activation of several signaling pathways [30-33]. In this study, we have confirmed that IL-6 and HMGB1 were released into the supernatant when HMVECs were infected with influenza A. IL-6 and HMGB1 are reported to be able to activate endothelial cells through several signaling pathways 
[34-37]. Although there have been no reports of IL-6 or HMGB 1 causing HMGB1 translocation, we could consider that the activation of HMVECs by IL-6 and HMGB1 led to HMGB1 translocation indirectly. Further studies are needed to understand the mechanism of HMGB1 translocation in certain surrounding cells and not in others.

We confirmed that anti-HMGB1 mAb was able to suppress the increased permeability upon TNF- $\alpha$ stimulation or influenza A infection. We also showed that anti-HMGB1 $m A b$ suppressed the change in cell morphology of HMVECs and the expanded intercellular space upon TNF- $\alpha$ stimulation or influenza A infection. TNF- $\alpha$ stimulation or influenza $A$ virus infection has been reported to increase vascular endothelial cell permeability [23, 25, 38]. High concentrations of HMGB1 have been reported to increase the vascular permeability in pulmonary vascular endothelial cells [39]. The HMGB1 receptors RAGE and TLR4 have already been reported to express abundantly on the surface of HMVECs [34, 40-42]. Extracellular HMGB1 binds to either RAGE or TLR4 on the surface of vascular endothelial cells and activates them via the p38MAPK pathway [25, 38, 43]. Activation of the p38MAPK pathway in vascular endothelial cells has been reported to increase the expression of F-actin, and to promote phosphorylation of ezrin/radixin/ moesin family proteins, leading to cytoskeletal changes and hyperpermeability [25, 38, 43]. In this study, we observed that HMGB1 was released following TNF- $\alpha$ stimulation or influenza A (H3N2) infection; this could lead to activation of HMVECs through RAGE and TLR4, changing the cytoskeleton to a spindle shape and expanding the intercellular spaces, thereby increasing the vascular permeability. It was considered that the anti-HMGB1 mAb suppressed the activation of HMVECs by neutralizing the released extracellular HMGB1 and inhibited the changes in cell morphology and the increase in permeability.

We confirmed that anti-HMGB $1 \mathrm{mAb}$ suppressed the production of cytokines/chemokines such as IL-6, G-CSF, GM-CSF, and IP-10 from HMVECs. Several studies show that TNF- $\alpha$ stimulation or influenza infection induces the secretion of inflammatory cytokines from HMVECs by activating the p38 MAPK and c-Jun N-terminal kinase pathways in endothelial cells [21, 25, 44]. Nuclear factor $\kappa \mathrm{B}$ is activated in endothelial cells, which is thought to increase the production of cytokines/chemokines [25, 43, 44]. IL-6 and IP-10 have been histopathologically found in pulmonary bronchial epithelial cells and endothelial cells of patients with severe influenza ARDS [45]. Clinically, high blood concentrations of IL-6, G-CSF, GM-CSF, and IP-10 have been reported to be indicators of the risk of death in patients with severe influenza pneumonia $[46,47]$. In particular, vascular endothelial cells express the IL-6 receptor and are directly activated by IL-6 via the Janus kinase-signal transducer and activator of transcription 3 pathway, resulting in the release of HMGB1 [35-37]. Our study suggests that anti-HMGB1 mAb suppresses the activation of HMVECs and prevents further exacerbation of hyperinflammation by specifically inhibiting extracellular HMGB1. As for IL-6, the anti-HMGB1 mAb inhibited further activation of HMVECs, which may have inhibited the release of IL-6 into the supernatant. By inhibiting extracellular HMGB1 and suppressing the release of IL-6, the activation of HMVECs by IL-6 may also have been suppressed. This might also inhibit the subsequent release of cytokines/chemokines and the morphological changes of the HMVECs. In terms of the relationship between antiHMGB $1 \mathrm{mAb}$ and HMVECs, anti-HMGB1 mAb might, not only directly inhibit the inflammatory effect of extracellular HMGB 1, but also indirectly inhibit IL-6-induced activation of HMVECs.

In this study, anti-HMGB $1 \mathrm{mAb}$ exerted the antiinflammatory effect by inhibiting extracellular HMGB1 from activating HMVECs. On the other hand, there was no effect of anti-HMGB $1 \mathrm{mAb}$ on the direct HMVEC activation due to TNF- $\alpha$ stimulation or influenza $A$ (H3N2) infection. Here we confirmed that the production of RANTES from HMVECs was not suppressed by anti-HMGB1 $\mathrm{mAb}$. This result indicates that the activation of HMVECs by extracellular HMGB1 was not mainly involved in RANTES production. IP-10 was produced in a much larger amount by influenza A (H3N2) infection than TNF- $\alpha$ stimulation. Since IP-10 production from HMVECs was decreased by treatment of anti-HMGB $1 \mathrm{mAb}$, activation of HMVECs by extracellular HMGB1 would be involved in IP-10 production. However, the IP-10 production owing to influenza A (H3N2) infection was so high that the inhibition of IP-10 by anti-HMGB $1 \mathrm{mAb}$ in influenza A (H3N2) infection needs to be carefully examined.

We observed that the effect of anti-HMGB $1 \mathrm{mAb}$ on HMVECs in suppressing hyper-permeability or cytokine/ chemokine production might be due to suppression of influenza A virus infection or propagation. Therefore, we evaluated the effect of anti-HMGB1 mAb on influenza A virus replication. The gene expression of influenza virus M1 protein increased after influenza A (H3N2) infection in a time-dependent manner. However, no decrease in viral M1 protein gene expression was observed, despite the introduction of the anti-HMGB $1 \mathrm{mAb}$. We previously reported that the administration of HMGB $1 \mathrm{mAb}$ improved the survival rate and inhibited the cytokine/ chemokine expression in the lungs, but it did not decrease virus propagation in vivo $[18,19]$, which is consistent with our observation in this study. We suppose that the inhibitory effect of hyper-permeability or cytokine/chemokine production observed in our study was not due to the inhibition of virus infection or replication, but to the inhibition of downstream inflammation after infection. 


\section{Conclusions}

We showed that an anti-HMGB $1 \mathrm{mAb}$ could suppress hyper-permeability and cytokine production in HMVECs caused by TNF- $\alpha$ stimulation or influenza A (H3N2) infection. These observations may facilitate the development of new therapeutic strategies for severe viral pneumonia and ARDS.

Acknowledgements This research was supported by Japan Agency for Medical Research and Development under Grant number JP20fk0108058

Author contributions TN, MT, MY, and TM designed the experiments. TN and MT performed the experimental work. KL and MN designed and prepared the anti-HMGB1 mAb. TN, MT, MY, YS, MN, and TM analyzed the data and interpreted the results. TN wrote the manuscript with help from MT, MY, MN, YS, TM, and HT. All authors read and approved the final manuscript.

Data availability All data generated or analyzed during this study are included in this published article.

\section{Declarations}

Conflict of interest The authors have no conflicts of interest to declare.

\section{References}

1. Dunning J, Thwaites RS, Openshaw PJM. Seasonal and pandemic influenza: 100 years of progress, still much to learn. Mucosal Immunol [Internet]. 2020;13:566-73. https://doi.org/ 10.1038/s41385-020-0287-5.

2. Krammer F, Smith GJD, Fouchier RAM, Peiris M, Kedzierska K, Doherty PC, et al. Influenza. Nat Rev Dis Prim. 2018;4:1-21.

3. Dawood FS, Iuliano AD, Reed C, Meltzer MI, Shay DK, Cheng P-Y, et al. Estimated global mortality associated with the first 12 months of 2009 pandemic influenza A H1N1 virus circulation: a modelling study. Lancet Infect Dis [Internet]. 2012;12:687-95.

4. Short KR, Kroeze EJBV, Fouchier RAM, Kuiken T. Pathogenesis of influenza-induced acute respiratory distress syndrome. Lancet Infect Dis [Internet]. 2014;14:57-69. https://doi.org/10. 1016/S1473-3099(13)70286-X.

5. Spadaro S, Park M, Turrini C, Tunstall T, Thwaites R, Mauri $\mathrm{T}$, et al. Biomarkers for acute respiratory distress syndrome and prospects for personalised medicine. J Inflamm (United Kingdom). 2019;16:1-11.

6. Short KR, Kuiken T, Van Riel D. Role of endothelial cells in the pathogenesis of influenza in humans. J Infect Dis. 2019;220:1859-60.

7. Torres A, Loeches IM, Sligl W, Lee N. Severe flu management: a point of view. Intensive Care Med [Internet]. 2020;46:153-62. https://doi.org/10.1007/s00134-019-05868-8

8. Shie JJ, Fang JM. Development of effective anti-influenza drugs: congeners and conjugates-a review. J Biomed Sci. 2019;26:1-20.

9. Liu Q, Zhou YH, Yang ZQ. The cytokine storm of severe influenza and development of immunomodulatory therapy. Cell Mol Immunol. 2016;13:3-10.
10. Hui DS, Lee N, Chan PK, Beigel JH. The role of adjuvant immunomodulatory agents for treatment of severe influenza. Antivir Res. 2018;150:202-16.

11. Lobo SM, Watanabe ASA, Salomão MLM, Queiroz F, Gandolfi JV, de Oliveira NE, et al. Excess mortality is associated with influenza $\mathrm{A}(\mathrm{H} 1 \mathrm{~N} 1)$ in patients with severe acute respiratory illness. J Clin Virol. 2019;116:62-8.

12. Arabi YM, Fowler R, Hayden FG. Critical care management of adults with community-acquired severe respiratory viral infection. Intensive Care Med [Internet]. 2020;46:315-28. https:// doi.org/10.1007/s00134-020-05943-5.

13. Ito $\mathrm{Y}$, Torii $\mathrm{Y}$, Ohta $\mathrm{R}$, Imai $\mathrm{M}$, Hara $\mathrm{S}$, Kawano $\mathrm{Y}$, et al. Increased levels of cytokines and high-mobility group box 1 are associated with the development of severe pneumonia, but not acute encephalopathy, in $2009 \mathrm{H} 1 \mathrm{~N} 1$ influenza-infected children. Cytokine [Internet]. 2011;56:180-7. https://doi.org/ 10.1016/j.cyto.2011.07.016.

14. Huang W, Tang Y, Li L. HMGB1, a potent proinflammatory cytokine in sepsis. Cytokine [Internet]. 2010;51:119-26. https:// doi.org/10.1016/j.cyto.2010.02.021.

15. Yang $\mathrm{H}$, Wang $\mathrm{H}$, Andersson U. Targeting inflammation driven by HMGB1. Front Immunol. 2020;11:1-9.

16. Andersson U, Ottestad W, Tracey KJ. Extracellular HMGB1: a therapeutic target in severe pulmonary inflammation including COVID-19? Mol Med. 2020;26(1):42.

17. Keyel PA. How is inflammation initiated? Individual influences of IL-1, IL-18 and HMGB1. Cytokine [Internet]. 2014;69:13645. https://doi.org/10.1016/j.cyto.2014.03.007.

18. Nosaka N, Yashiro M, Yamada M, Fujii Y, Tsukahara H, Liu $\mathrm{K}$, et al. Anti-high mobility group box-1 monoclonal antibody treatment provides protection against influenza A virus (H1N1)induced pneumonia in mice. Crit Care [Internet]. 2015;19:1-9. https://doi.org/10.1186/s13054-015-0983-9.

19. Hatayama K, Nosaka N, Yamada M, Yashiro M, Fujii Y, Tsukahara $\mathrm{H}$, et al. Combined effect of anti-high-mobility group box-1 monoclonal antibody and peramivir against influenza A virusinduced pneumonia in mice. J Med Virol. 2019;91(3):361-9.

20. Chan MCW, Chan RWY, Yu WCL, Ho CCC, Chui WH, Lo $\mathrm{CK}$, et al. Influenza H5N1 virus infection of polarized human alveolar epithelial cells and lung microvascular endothelial cells. Respir Res. 2009;10:1-12.

21. Zeng H, Pappas C, Belser JA, Houser KV, Zhong W, Wadford DA, et al. Human pulmonary microvascular endothelial cells support productive replication of highly pathogenic avian influenza viruses: possible involvement in the pathogenesis of human H5N1 virus infection. J Virol. 2012;86:667-78.

22. Saito Y, Fujii Y, Yashiro M, Tsuge M, Nosaka N, Yamashita N, et al. Inhibitory effects of edaravone, a free radical scavenger, on cytokine-induced hyperpermeability of human pulmonary microvascular endothelial cells: a comparison with dexamethasone and nitric oxide synthase inhibitor. Acta Med Okayama. 2015;69:279-90.

23. Armstrong SM, Wang C, Tigdi J, Si X, Dumpit C, Charles S, et al. Influenza infects lung microvascular endothelium leading to microvascular leak: role of apoptosis and claudin-5. PLoS One. 2012;7(10):e47323.

24. Liu K, Mori S, Takahashi HK, Tomono Y, Wake H, Kanke T, et al. Anti-high mobility group box 1 monoclonal antibody ameliorates brain infarction induced by transient ischemia in rats. FASEB J. 2007;21:3904-16.

25. Zhang C, Wu Y, Xuan Z, Zhang S, Wang X, Hao Y, et al. P38MAPK, Rho/ROCK and PKC pathways are involved in influenza-induced cytoskeletal rearrangement and hyperpermeability in PMVEC via phosphorylating ERM. Virus Res [Internet]. 2014;192:6-15. https://doi.org/10.1016/j.virusres.2014.07. 027. 
26. Nguyen-Van-Tam JS. 2009 pandemic influenza A/H1N1. Environ Med [Internet]. 2010;177:221-3. https://doi.org/10.2353/ajpath. 2010.100115.

27. Yang WS, Han NJ, Kim JJ, Lee MJ, Park SK. TNF- $\alpha$ activates high-mobility group box 1 -toll-like receptor 4 signaling pathway in human aortic endothelial cells. Cell Physiol Biochem. 2016;38:2139-51.

28. Hosakote YM, Brasier AR, Casola A, Garofalo RP, Kurosky A. Respiratory syncytial virus infection triggers epithelial HMGB1 release as a damage-associated molecular pattern promoting a monocytic inflammatory response. J Virol. 2016;90:9618-31.

29. Barqasho B, Nowak P, Abdurahman S, Walther-Jallow L, Sönnerborg A. Implications of the release of high-mobility group box 1 protein from dying cells during human immunodeficiency virus type 1 infection in vitro. J Gen Virol. 2010;91:1800-9.

30. Huang W, Xie W, Gong J, Wang W, Cai S, Huang Q, et al. Heat stress induces RIP1/RIP3-dependent necroptosis through the MAPK, NF- $\mathrm{KB}$, and c-Jun signaling pathways in pulmonary vascular endothelial cells. Biochem Biophys Res Commun [Internet]. 2020;528:206-12. https://doi.org/10.1016/j.bbrc.2020.04.150.

31. Rabadi MM, Kuo MC, Ghaly T, Rabadi SM, Weber M, Goligorsky MS, et al. Interaction between uric acid and HMGB1 translocation and release from endothelial cells. Am J Physiol Ren Physiol. 2012;302:730-41

32. Shao M, Tang ST, Liu B, Zhu HQ. Rac1 mediates HMGB1induced hyperpermeability in pulmonary microvascular endothelial cells via MAPK signal transduction. Mol Med Rep. 2016;13:529-35.

33. Lu B, Antoine DJ, Kwan K, Lundbäck P, Wähämaa H, Schierbeck $\mathrm{H}$, et al. JAK/STAT1 signaling promotes HMGB1 hyperacetylation and nuclear translocation. Proc Natl Acad Sci USA. 2014;111:3068-73.

34. Fiuza C, Bustin M, Talwar S, Tropea M, Gerstenberger E, Shelhamer $\mathrm{JH}$, et al. Inflammation-promoting activity of HMGB1 on human microvascular endothelial cells. Blood. 2003;101:2652-60.

35. Yin Y, Feng Y, Zhao H, Zhao Z, Yua H, Xu J, et al. SIRT1 inhibits releases of HMGB1 and HSP70 from human umbilical vein endothelial cells caused by IL- 6 and the serum from a preeclampsia patient and protects the cells from death. Biomed Pharmacother. 2017;88:449-58.

36. Yun JH, Han MH, Jeong HS, Lee DH, Cho CH. Angiopoietin 1 attenuates interleukin-6-induced endothelial cell permeability through SHP-1. Biochem Biophys Res Commun. 2019;518:286-93.

37. Zegeye MM, Lindkvist M, Fälker K, Kumawat AK, Paramel G, Grenegård $\mathrm{M}$, et al. Activation of the JAK/STAT3 and PI3K/
AKT pathways are crucial for IL-6 trans-signaling-mediated proinflammatory response in human vascular endothelial cells. Cell Commun Signal. 2018;16:1-10.

38. Hiyoshi M, Indalao IL, Yano M, Yamane K, Takahashi E, Kido H. Influenza A virus infection of vascular endothelial cells induces GSK-3 $\beta$-mediated $\beta$-catenin degradation in adherens junctions, with a resultant increase in membrane permeability. Arch Virol. 2015;160:225-34.

39. Rachel K, Wolfson ETC, Garcia JGN. HMGB1 induces human lung endothelial cell cytoskeletal rearrangement and barrier disruption. Microvasc Res. 2011;81:189-97.

40. Mangalmurti NS, Chatterjee S, Cheng G, Andersen E, Mohammed A, Siegel DL, et al. Advanced glycation end products on stored red blood cells increase endothelial reactive oxygen species generation through interaction with receptor for advanced glycation end products. Transfusion. 2010;50:2353-61.

41. Khakpour S, Wilhelmsen K, Hellman J. Vascular endothelial cell Toll-like receptor pathways in sepsis. Innate Immun. 2015;21:827-46.

42. Li Y, Xiang M, Yuan Y, Xiao G, Zhang J, Jiang Y, et al. Hemorrhagic shock augments lung endothelial cell activation: role of temporal alterations of TLR4 and TLR2. Am J Physiol Regul Integr Comp Physiol. 2009;297:1670-80.

43. Uhlig S, Yang Y, Waade J, Wittenberg C, Babendreyer A, Kuebler WM. Differential regulation of lung endothelial permeability in vitro and in situ. Cell Physiol Biochem. 2014;34(1):1-19.

44. Wu Y, Huang H. Synergistic enhancement of matrix metalloproteinase- 9 expression and pro-inflammatory cytokines by influenza virus infection and oxidized-LDL treatment in human endothelial cells. Exp Ther Med. 2017;14:4579-85.

45. Nakajima N, Van Tin N, Sato Y, Thach HN, Katano H, Diep $\mathrm{PH}$, et al. Pathological study of archival lung tissues from five fatal cases of avian H5N1 influenza in Vietnam. Mod Pathol. 2013;26:357-69.

46. Hall MW, Geyer SM, Guo CY, Panoskaltsis-Mortari A, Jouvet $\mathrm{P}$, Ferdinands $\mathrm{J}$, et al. Innate immune function and mortality in critically III children with influenza: a multicenter study. Crit Care Med. 2013;41:224-36.

47. Bradley-Stewart A, Jolly L, Adamson W, Gunson R, FrewGillespie C, Templeton K, et al. Cytokine responses in patients with mild or severe influenza A (H1N1)pdm09. J Clin Virol [Internet]. 2013;58:100-7. https://doi.org/10.1016/j.jcv.2013.05. 011.

Publisher's Note Springer Nature remains neutral with regard to jurisdictional claims in published maps and institutional affiliations. 